\title{
Consumption of sodium chloride and lithium chloride in normal rats and in rats with septal lesions*
}

\author{
LEONARD W. HAMILTON $\uparrow$ and SALVATORE CAPOBIANCO \\ Rutgers Liniversity, New Brunswick, Vew Jersey 08903
}

\begin{abstract}
Rats were trained to consume their daily fluid requirements by drinking a dilute $(.077 \mathrm{M}) \mathrm{NaCl}$ solution during a 20-min test session. In Experiment $\mathrm{I}$. an equimolar solution of $\mathrm{LiCl}$ was introduced on test days. Following the first exposure to $\mathrm{LiCl}$, conditioned aversion to $\mathrm{NaCl}$ was observed. With repeated exposures, the conditioned aversion declined and the rats learned to discriminate the $\mathrm{LiCl}$ during the test session, suggesting that the onset of the aversive consequences of $\mathrm{LiCl}$ ingestion was rapid. Experiment $\mathrm{II}$, which was designed to measure the time course of the onset of $\mathrm{LiCl}$ illness. confirmed the results of Experiment I. In both experiments, rats with septal lesions were more reactive to the aversive postingestive effects of $\mathrm{LiCl}$. In Experiment III, taste differences were introduced by changing the concentration of the $\mathrm{LiCl}$. Rats with septal lesions were more reactive to these differences in taste.
\end{abstract}

During the past few years. there has been a revival of interest in the phenomenon which Barnett (1963) and others have described as bait shyness. To a large extent, this renewed interest has been attributable to the development of more refined methodology and a realization of the importance of this phenomenon for theories of learning [see Garcia and Ervin (1968) for a review of this literature]. A typical example of a procedure that can be used to demonstrate bait shyness or conditioned aversions is as follows: A group of rats is allowed to consume a novel food substance. Following the consumption of this substance. one half of the animals receive a substance which causes illness and the other half receive a placebo. Subsequent tests indicate that the rats which became ill will reject the food substance, thereby demonstrating a conditioned gustatory aversion.

According to Garcia and Ervin (1968), this is a gustatory learning phenomenon in which the taste of the substance represents the conditional stimulus and the aversive postingestional effects represent the unconditional stimulus. As in more conventional learning paradigms (e.g., Carlton \& Vogel, 1967), previous exposures to the conditional stimulus in the absence of association with an aversive stimulus leads to much slower learning. Thus, the conditioned gustatory aversion takes place much more readily if the taste of the food substance is novel.

Of particular relevance to the present investigation are the data concerning lithium chloride $(\mathrm{LiCl})$, a poisonous salt. A number of investigators (e.g., Garcia \& Koelling, 1967) have shown that intraperitoneal injections of $\mathrm{LiCl}$ following the ingestion of a novel food substance will

\footnotetext{
*This research was supported by the L.S.P.H.S. through Grant MH16448 awarded to L. Hamilton and an NIMH predoctoral fellowship awarded to S. Capobianco.

$\div$ Requests for reprints should be mailed to Leonard Hamilton. Department of Psychology. Rutgers Lniversity, New Brunswick. New Jersey 08903.
}

lead to strong conditioned aversion for the food substance. Nachmann (1963) has shown that the conditioned aversion resulting from the ingestion of a $\mathrm{LiCl}$ solution generalizes to other solutions (e.g., $\mathrm{NaCl}$ and $\mathrm{KCl}$ ) and to other concentrations. In fact, Nachmann concluded that rats are unable to discriminate between equimolar concentrations of $\mathrm{NaCl}$ and $\mathrm{LiCl}$.

If Nachmann is correct in his assertion that rats are unable to discriminate $\mathrm{NaCl}$ from $\mathrm{LiCl}$ on the basis of taste, then any discrimination that develops would necessarily be based upon postingestional cues. It was this relationship of apparently identical taste factors, but radically different postingestional cues which provided the impetus for the present series of experiments.

It has been known for some time that rats with septal lesions are more responsive to taste factors, drinking excessive quantities of preferred solutions such as saccharin while rejecting solutions flavored with an aversive substance such as quinine (e.g., Beatty \& Schwartzbaum, 1967). More recent investigations from this laboratory (e.g., Hamilton, 1971) have indicated that this heightened reactivity to taste factors is coupled with a decrease in responsivity to postingestional cues-at least those associated with nutritive substances. If this decrease in responsivity to postingestional cues can be extended beyond the case of nutritive substances. then the prediction is clear that rats with septal lesions should have more difficulty than normal rats in discriminating between $\mathrm{NaCl}$ and $\mathrm{LiCl}$.

\section{EXPERIMENT I}

In this experiment, rats were trained to consume their entire daily fluid intake during a 20 -min session in a testing cage. After a baseline of drinking was established using a $\mathrm{NaCl}$ solution. $\mathrm{LiCl}$ test sessions were interspersed to determine the ability of the rats to discriminate the aversive postingestive effects of this poisonous salt. 


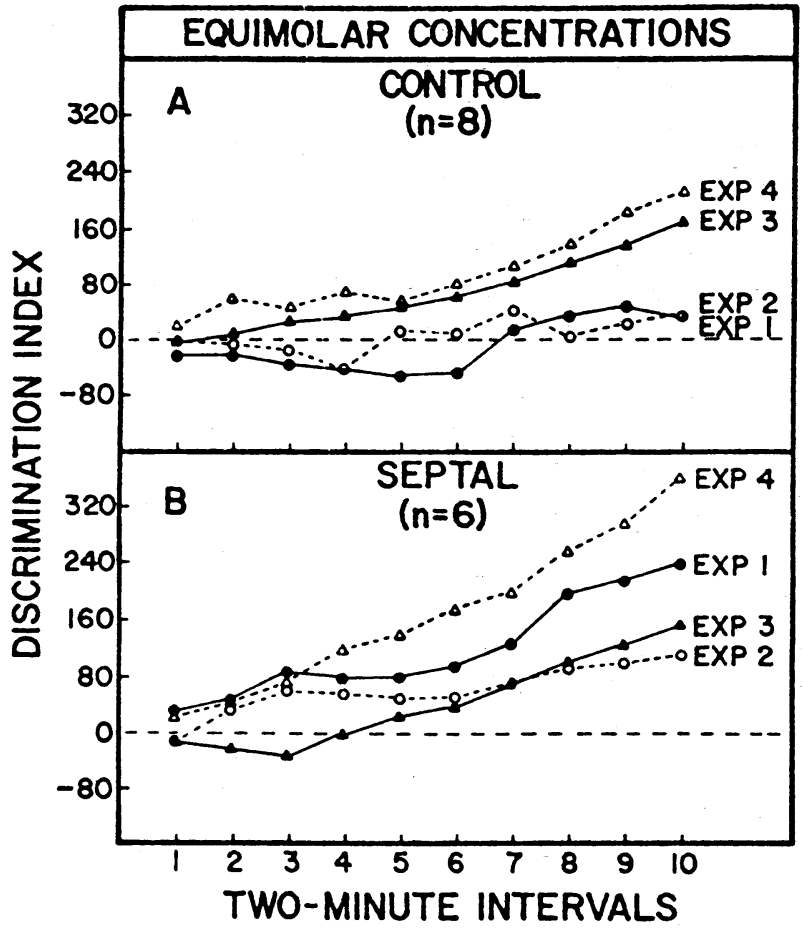

Fig. 1. Index of discrimination of equimolar concentrations of $\mathrm{LiCl}$ and $\mathrm{NaCl}$ as a function of repeated exposures (EXP) to LiCl. Positive numbers indicate low intake of $\mathrm{LiCl}$ relative to $\mathrm{NaCl}$ (see text for full explanation).

\section{Method}

\section{Subjects}

The Ss were 16 adult male Sprague-Dawley descendents obtained from Carworth (CFE strain). Body weights ranged from 200 to $250 \mathrm{~g}$ at the time of testing. The rats were housed singly with ad lib access to food and water, except as noted below. All testing was conducted during the light portion of a $16 / 8$ light/dark cycle.

\section{Surgical and Histological Procedures}

All rats were anesthetized with $0.23-0.26 \mathrm{cc} / 100 \mathrm{~g}$ body weight of Equithesin (Jensen-Salsbery) and positioned in a stereotaxic instrument (Kopf). Burr holes were drilled into the skulls of one-half of the rats which served as operated controls. For the remaining rats, a stainless steel electrode (insulated except for the tip) was lowered bilaterally to the following deGroot (1959) coordinates: $\mathrm{AP}=7.6, \mathrm{~L}=0.8$, and $\mathrm{H}=2.0 \mathrm{~mm}$. The lesion was produced by passing anodal current $(1.0 \mathrm{~mA}$ for $12 \mathrm{sec}$ ) between the electrode tip and indifferent electrode clipped to the edge of the scalp incision.

Upon completion of behavioral testing, the experimental rats were perfused intracardially with saline, followed by Formol saline. The brains were removed from the skull and stored in a glucose Formalin solution prior to sectioning. The 50 -micron frozen sections were mounted on slides and stained with cresyl violet. Microscopic examination of the stained tissue was used to determine the locus and extent of the damage incurred by the lesion. Two experimental rats were dropped on the basis of histological examination.

\section{Testing Procedures}

At the beginning of the experiment, the water bottles were removed from the home cages, and the rats were required to consume their entire daily intake during a 20 -min test session. The testing cage was a Plexiglas box, $20 \times 21 \times 21 \mathrm{~cm}$ high, with a wire mesh floor (1.3-cm openings). A Plexiglas tube, $12 \mathrm{~cm}$ long and $5 \mathrm{~cm}$ in diam, was centered on one wall $5.5 \mathrm{~cm}$ above the floor. A metal drinking tube was recessed $2 \mathrm{~cm}$ into this tube. The tube was connected to a drinkometer circuit such that a drinking bout produced a continuous output into a timer. The duration of drinking (seconds) was automatically recorded for each 2-min interval of the 20 -min testing session.

During most of the sessions, a $0.77 \mathrm{M}$ solution of $\mathrm{NaCl}$ $(4.50 \mathrm{~g} /$ liter $)$ was available from the drinking tube. On Days 5 , 11,16 , and 22 , the solution was changed to a $0.77 \mathrm{M} \mathrm{LiCl}$ solution ( $3.26 \mathrm{~g} /$ liter). The days on which the $\mathrm{LiCl}$ solution was administered were determined on the basis of the $\mathrm{NaCl}$ baseline.

\section{Statistical Analyses}

The statistical analyses were based upon 3-day blocks, which included a lithium test day. For each rat, the cumulative duration (seconds) of drinking across the 102 -min intervals was determined for the pretest day $(\mathrm{NaCl})$, the $\mathrm{LiCl}$ day, and the posttest day $(\mathrm{NaCl})$. These scores were used to tabulate indices of discrimination and conditioned aversion: The discrimination index was calculated by subtracting the scores of the $\mathrm{LiCl}$ day from those of the pretest day, the rationale being that any differences between these two sets of scores should be based upon the ability of the rats to discriminate $\mathrm{LiCl}$ from $\mathrm{NaCl}$. The conditioned aversion index was calculated by subtracting the scores of the posttest day from those of the pretest day, the rationale being that any differences between these two sets of scores should be based upon the conditioned gustatory aversion toward salty tastes resulting from the $\mathrm{LiCl}$-induced illness which occurred on the intervening day. These two sets of indices were calculated for each exposure to the $\mathrm{LiCl}$ solution.

Separate two-factor analyses of variance (repeated measures) were performed to determine changes in these indices as a function of successive exposures to $\mathrm{LiCl}$ and as a function of time within the experimental session. Comparisons of individual means were made using Duncan's (1955) multiple-range test based upon the appropriate analysis of variance. All differences which are reported below as being significant differed beyond the .05 level of confidence according to the Duncan test.

\section{Results}

\section{Control Rats}

The control Ss showed no evidence of discrimination between $\mathrm{NaCl}$ and $\mathrm{LiCl}$ solutions until the third exposure to the poisonous $\mathrm{LiCl}$ solution (see Fig. 1A). During the third exposure, the discrimination index increased significantly as a function of time, with the last three intervals differing significantly from Interval 1. By the fourth exposure, the discrimination became apparent even more rapidly, reaching significance by the seventh interval (i.e., within $14 \mathrm{~min}$ ).

The conditioned aversion index revealed a nonsignificant trend for conditioned aversion following Exposure 1, but no evidence for conditioned aversion following subsequent exposures (see Fig. 2A). The initial failure for conditioned aversion to develop would be expected on the basis of familiarity with the taste 
substance (if the taste of $\mathrm{LiCl}$ is identical to that of $\mathrm{NaCl}$, it would not be treated as a novel substance). During later exposures, as the discrimination developed on the basis of within-session postingestive effects, there would have been no basis for rejection of the $\mathrm{NaCl}$ solution.

\section{Experimental Rats}

The rats with septal lesions showed a significant discrimination of the $\mathrm{LiCl}$ in each of the four exposures (see Fig. 1B). Although a similar increase in the discrimination index was observed for control rats during Exposure 4, comparison of Figs. $1 \mathrm{~A}$ and $1 \mathrm{~B}$ indicates that the rats with septal lesions made this discrimination sooner than did controls. The discrimination index for Exposure 4 increased rapidly as a function of intervals, with the index for the fifth interval (and all succeeding intervals) being significantly different from that of the first interval. This indicates that the discrimination had taken place within $10 \mathrm{~min}$ following the onset of drinking, and the slope of the curve suggests that this discrimination may have been exhibited within 4 to $6 \mathrm{~min}$. The rapidity of this discrimination under conditions of high deprivation suggests either that the discrimination may be based upon taste rather than postingestional cues or that the illness resulting from the $\mathrm{LiCl}$ was detected within a few' minutes.

The conditioned aversion index revealed that the rats with septal lesions showed a significant rejection of the $\mathrm{NaCl}$ solution following the first two exposures to the $\mathrm{LiCl}$ solution (see Fig. 2B). There was no rejection of $\mathrm{NaCl}$ following either the third or fourth exposures to $\mathrm{LiCl}$ (as indicated in the figure, there was an unexplainable increase in $\mathrm{NaCl}$ intake following Exposure 3). Assuming that the ability to discriminate the two solutions was initially somewhat marginal, these data suggest the possibility that familiarity with a salty taste was less effective for septal rats than for normal rats in reducing the degree of conditioned aversion. Once the discrimination had developed, however, both groups of rats accepted the $\mathrm{NaCl}$ solution following the $\mathrm{LiCl}$ test day.

\section{EXPERIMENT II}

This experiment was designed to investigate the time course of the onset of illness accompanying the ingestion of $\mathrm{LiCl}$. The results of the previous experiment suggested that normal rats can learn to discriminate $\mathrm{LiCl}$ from $\mathrm{NaCl}$ with repeated exposures. It should be noted. however, that the rats were pretrained to drink a solution of $\mathrm{NaCl}$ prior to the first exposure to $\mathrm{LiCl}$. This prior experience with a salty taste that was not associated with illness should have rendered the rats less sensitive to the aversive postingestive effects of the $\mathrm{LiCl}$ during the first exposure to the poisonous substance. In

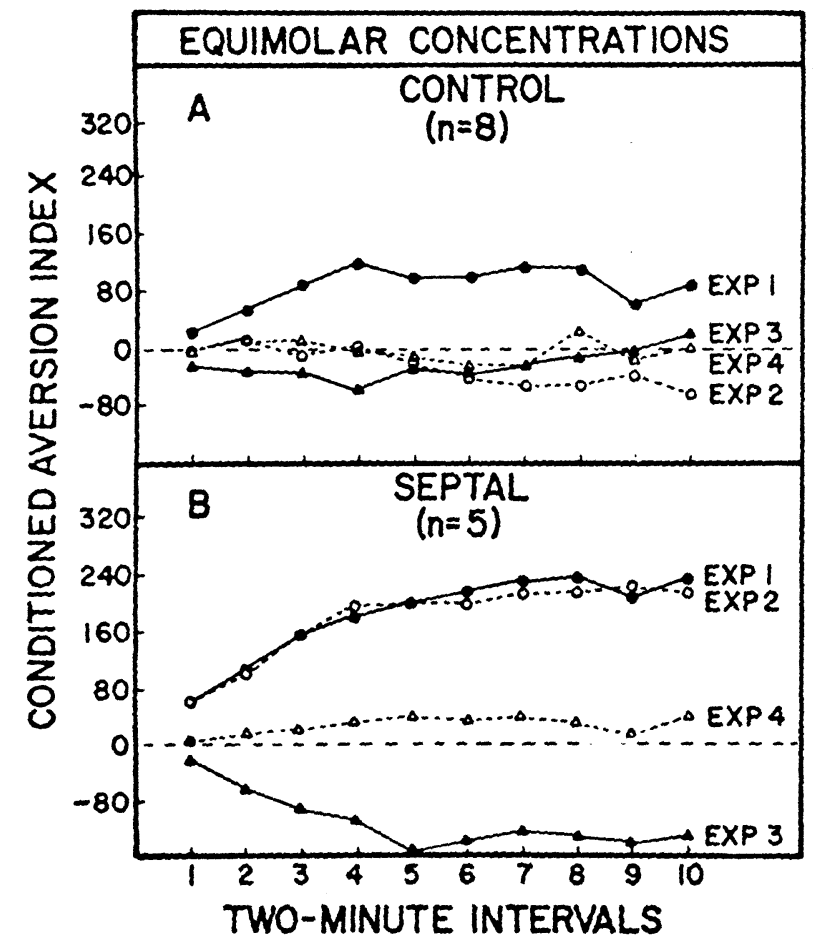

Fig. 2. Index of conditioned aversion to $\mathrm{NaCl}$ as a function of repeated exposures (EXP) to an equimolar solution of $\mathrm{LiCl}$. Positive numbers indicate low $\mathrm{NaCl}$ intake relative to that which preceded the $\mathrm{LiCl}$ test day (see text for full explanation).

the present experiment, the rats that received $\mathrm{LiCl}$ had had no prior experience with salty solutions. This lack of prior experience should lead to neophobia associated with the $\mathrm{LiCl}$ intake and should prime the organism to monitor postingestive events. The present experiment was also designed to test the possibility that rats with septal lesions are more receptive to the aversive postingestive effects of $\mathrm{LiCl}$, as suggested in Experiment I.

\section{Method}

\section{Subjects}

The 32 Ss were similar to those used in the previous experiment, weighing $200-380 \mathrm{~g}$ at the time of testing.

\section{Surgical and Histological Procedures}

The surgical and histological procedures were the same as those used in Experiment I. The lesions involved extensive bilateral damage to the septal nuclei anterior to anterior commissure and to the medial parolfactory area. There was no damage to the caudate nuclei and only slight damage to the corpus callossum. In only one case did the lesion extend posteriorly into the triangular nucleus and the columns of the fornix.

\section{Testing Procedures}

All testing was conducted in the home cage. with intake being measured through the use of calibrated bottles.

At the beginning of the experiment, the rats were deprived of 


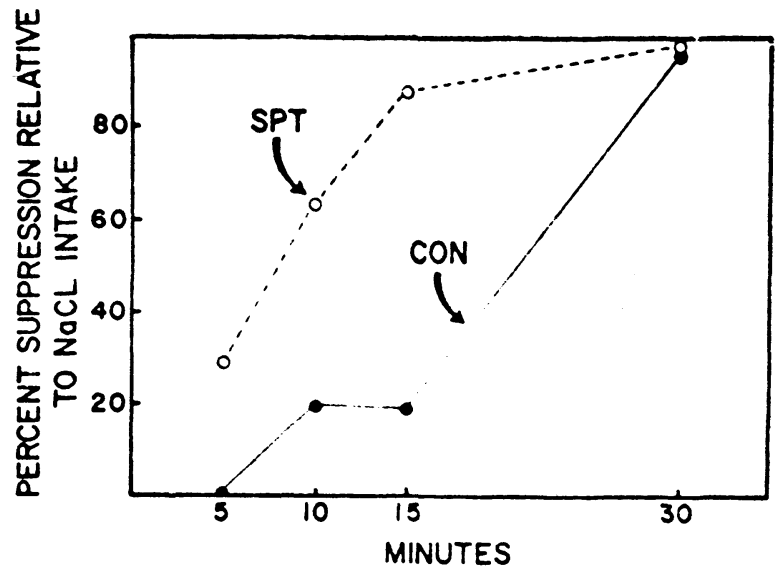

Fig. 3. Suppression of $\mathrm{LiCl}$ intake during the first exposure relative to the $\mathrm{NaCl}$ intake of a separate group.

water for $23.5 \mathrm{~h}$. At the end of this deprivation period, the rats were presented a solution of either $\mathrm{NaCl}$ or $\mathrm{LiCl}(0.077 \mathrm{M}$ in both cases). Eight control rats and eight experimental rats were in each of the subgroups. The intake of the solution was recorded at $5,10,15$, and $30 \mathrm{~min}$.

\section{Results}

The mean intake of $\mathrm{NaCl}$ during the 30-min test session was 15.2 and $21.1 \mathrm{ml}$, respectively, for the control rats and the rats with septal lesions. Although this difference was not statistically significant $(\mathrm{t}<1)$, the trend for higher intake following septal lesions was taken into account by expressing the suppression of intake of $\mathrm{LiCl}$ as a percentage of the mean $\mathrm{NaCl}$ intake for each interval. As shown in Fig. 3, the rats with septal lesions were significantly more responsive than the control rats to the $\mathrm{LiCl}$ solution $(\mathrm{F}=7.32, \mathrm{df}=1 / 14$, $\mathrm{p}<.05)$. The analysis of variance revealed that the interval effect was highly significant $(\mathrm{F}=10.43$, $\mathrm{df}=$ $3 / 42, p<.001$ ) with virtually no drinking by the end of $30 \mathrm{~min}$. Although the apparent interaction did not reach statistical significance, application of the Duncan multiple-range test revealed that the rats with septal lesions showed significantly more suppression than the control rats at the end of $15 \mathrm{~min}(\mathrm{p}<.05)$. These results clearly show that the internal changes resulting from $\mathrm{LiCl}$ ingestion are capable of almost totally stopping intake within $30 \mathrm{~min}$ on the first exposure (even faster following septal lesions). With the development of conditioned aversion and closer monitoring of internal changes, it is not unreasonable to assume that the solutions can be discriminated within a few minutes strictly on the basis of internal cues.

\section{EXPERIMENT III}

The results of Experiments I and II indicated that both normal rats and rats with septal lesions can learn to discriminate $\mathrm{LiCl}$ from $\mathrm{NaCl}$ within the first few minutes of the test session. This discrimination, although rapid, appeared to be based upon the postingestive cues associated with the initial stages of the illness that follows $\mathrm{LiCl}$ ingestion. The present experiment was designed to assess the role of taste factors in conditioned aversion following septal lesions. The procedures were very similar to those used in Experiment $I$, except that small taste differences were experimentally introduced by using solutions of slightly differing molarity.

\section{Method}

Subjects

The 16 Ss were similar to those used in Experiments I and II, with body weights ranging from 206 to $330 \mathrm{~g}$ at the time of testing.

\section{Surgical and Histological Procedures}

The surgical and histological procedures were the same as those used in the previous experiments. Two experimental rats were dropped on the basis of the histological examination. For the remaining rats, extensive bilateral damage to the septal nuclei was incurred anterior and dorsal to the level of the anterior commissure. The lesions did not damage the caudate nuclei, and damage to the corpus callossum was slight.

\section{Testing Procedures}

The testing procedures were the same as those used for Experiment I, except that the $\mathrm{LiCl}$ solution was administered on Days $4,9,11$, and 12 . The third and fourth exposures were administered consecutively in this experiment to determine if the rapid dissipation of conditioned aversion (see results) was due to increasing thirst or to discrimination of the $\mathrm{LiCl}$ from the $\mathrm{NaCl}$.

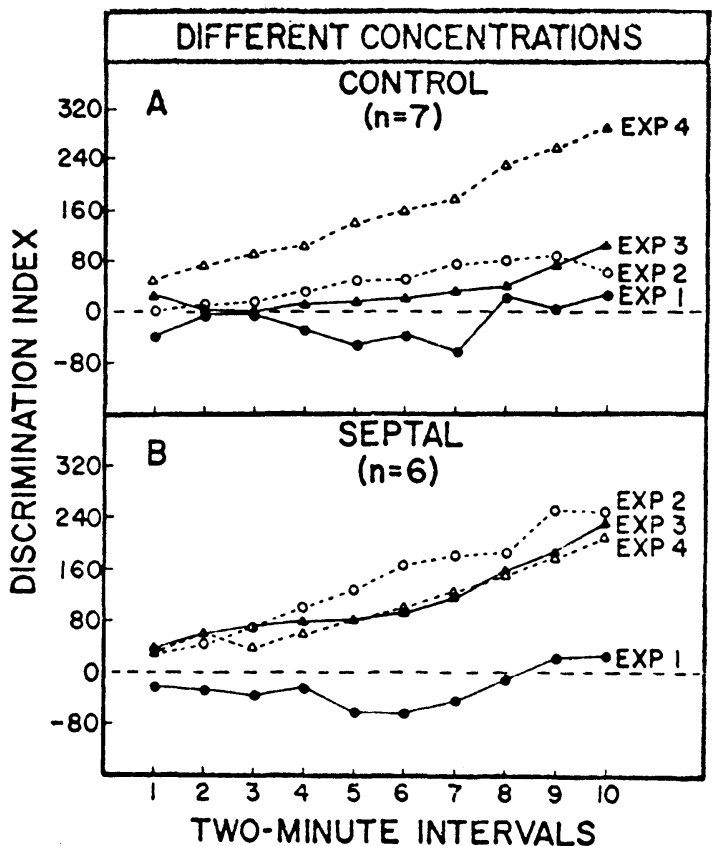

Fig. 4. Index of discrimination of $.077 \mathrm{M} \mathrm{NaCl}$ and $.106 \mathrm{M}$ $\mathrm{LiCl}$ as a function of repeated exposures (EXP) to the $\mathrm{LiCl}$ solution. Positive numbers indicate low intake relative to $\mathrm{NaCl}$ (see text for full explanation). 
The $\mathrm{NaCl}$ solution was identical to that used in Experiment I $(.077 \mathrm{M})$. The $\mathrm{LiCl}$ solution was $.106 \mathrm{M}(4.5 \mathrm{~g} / \mathrm{liter})$.

\section{Statistical Analyses}

The statistical analyses were identical to those used in Experiment I. Because the last two exposures to $\mathrm{LiCl}$ occurred consecutively, the conditioned aversion index was calculated for Exposures 1 and 2 only.

\section{Results}

\section{Control Rats}

The results of the previous experiments indicated that relatively rapid discriminations can be made between equimolar solutions of $\mathrm{NaCl}$ and $\mathrm{LiCl}$ on the basis of postingestive cues. In the present experiment, a slight difference in the molarity of the solutions was introduced to provide taste cues for discrimination. For the control rats, the discrimination index revealed no evidence for discrimination during Exposure 1 and only slight indications of discrimination during Exposures 2 and 3 (see Fig. 4A). By the fourth exposure, a clear discrimination was shown.

The index of condition aversion revealed a significant rejection of $\mathrm{NaCl}$ following the first exposure to $\mathrm{LiCl}$, presumably attributable to poor discriminability of the two solutions (see Fig. 5A). There was, however, no evidence for conditioned aversion following the second exposure to $\mathrm{LiCl}$, indicating that the discrimination was already developing.

\section{Experimental Rats}

The rats with septal lesions showed no discrimination during the first exposure to $\mathrm{LiCl}$, but showed significant discrimination during all subsequent exposures (see Fig. 4B). The more rapid development of this discrimination, relative to the control rats, provides further support for the heightened taste reactivity following these lesions in other testing situations.

The results of Experiments I and II have shown that rats were capable of discriminating between equimolar solutions of $\mathrm{LiCl}$ and $\mathrm{NaCl}$, presumably as a result of the rapid onset of aversive postingestive cues which are associated with the illness produced by the poisonous $\mathrm{LiCl}$ salt. In both of these experiments, rats with septal lesions were more reactive to these postingestive cues-an effect which contradicts the results of experiments investigating the responsiveness to the postingestive consequences of nutritive substances (e.g., Flaherty \& Hamilton, 1971; Hamilton, 1971). These findings, together with those of the present study, suggest that septal lesions may reduce reactivity to nutritive or positive postingestive stimuli while enhancing reactivity to aversive or negative postingestive stimuli.

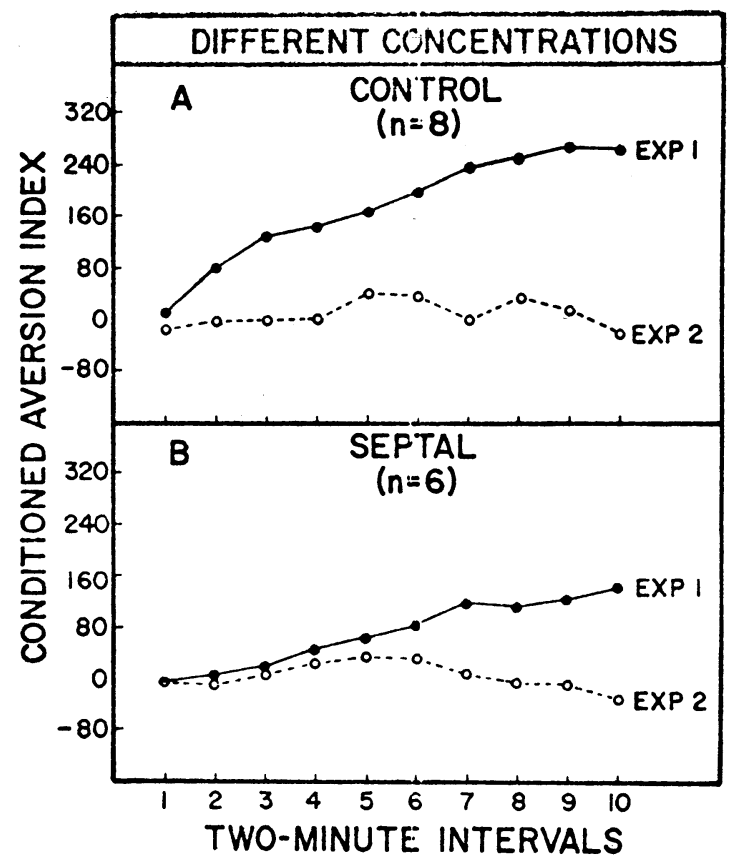

Fig. 5. Index of conditioned aversion to $0.77 \mathrm{M} \mathrm{NaCl}$ as a function of repeated exposures (EXP) to $.106 \mathrm{M} \mathrm{LiCl}$. Positive numbers indicate low $\mathrm{NaCl}$ intake relative to that which preceded the $\mathrm{LiCl}$ test day (see text for full explanation).

The results of Experiment III are consistent with numerous previous studies which have shown exaggerated taste reactivity following septal lesions (e.g., Beatty \& Schwartzbaum, 1967; Flaherty \& Hamilton, 1971). Not only did the discrimination index reveal a more rapid development of discrimination within the session, but the relatively small degree of conditioned aversion evidenced by the experimental rats suggested that the illness was rather specifically associated with the taste of the $\mathrm{LiCl}$ solution. This phenomenon is apparently a very general one which extends across a variety of solutions and solution concentrations for both positive and negative taste factors.

\section{REFERENCES}

Barnett, S. A. The rat: A study of behavior. Chicago: Aldine, 1963.

Beatty, W. W., \& Schwartzbaum, J. S. Enhanced reactivity to quinine and saccharine solutions following septal lesions in the rat. Psychonomic Science, 1967, 8, 483-484.

Carlton, P. L., \& Vogel, J. Habituation and conditioning. Journal of Comparative \& Physiological Psychology, 1967, 63, 348-351.

deGroot, J. The rat forebrain in stereotaxic coordinates. Amsterdam: Noorde-Hallansche Uitgevers Maatschappij, 1959.

Duncan, D. B. Multiple range and multiple F tests. Biometrics, $1955,11,1-42$.

Flaherty, C. F., \& Hamilton, L. W. Responsivity to decreasing sucrose concentrations following septal lesions in the rat. Physiology \& Behavior, 1971, 6, 431-437.

Garcia, J., \& Ervin, F. R. Gustatory-visceral and 
telereceptor-cutaneous conditioning-adaptation in internal and external milieus. Communications in Behavioral Biology, 1968, Part A, 1, 389-415.

Garcia, J., \& Koelling, R. A. A comparison of aversions induced by X-rays, drugs and toxins. Radiation Research, 1967, Supplement 7, 439-450.

Hamilton. L. W. Starvation induced by sucrose ingestion in the rat: Partial protection by septal lesions. Journal of
Comparative \& Physiological Psychology, 1971, 77, 59-69.

Nachmann, M. Learned aversion to the taste of lithium chloride and its generalization to other salts. Journal of Comparative \& Physiological Psychology, 1963, 56, 343-349.

(Received for publication January 26, 1973; accepted March 15, 1973.) 